\title{
Regulation of Kappa Opioid Receptor Inactivation Depends on Sex and Cellular Site of Antagonist Action
}

\author{
Kathryn L. Reichard, Keionna A. Newton, Zeena M.G. Rivera, Paulo M. Sotero de Menezes, \\ Selena S. Schattauer, Benjamin B. Land, and Charles Chavkin
}

Neurobiology of Addiction, Pain, and Emotion (K.L.R., K.A.N., Z.M.G.R., P.M.S. ., S.S.S., B.B.L., C.C.), University of Washington Department of Pharmacology (K.L.R., K.A.N., Z.M.G.R., P.M.S.M. S.S.S., B.B.L., C.C.), University of Washington Graduate Program in Neuroscience (K.L.R., C.C.), Seattle, Washington

Received July 21, 2020; accepted August 27, 2020

\section{ABSTRACT}

The prototypical member of the receptor-inactivating kappa opioid receptor (KOR) antagonists, norbinaltorphimine (norBNI), produces prolonged receptor inactivation by a cJun kinase mechanism. These antagonists have potential therapeutic utility in the treatment of stress disorders; however, additional preclinical characterization is necessary to understand important aspects of their action. In this study, we report that norBNI does not work as effectively in female mice as in males because of estrogen regulation of $G$ protein receptor kinase (GRK); pretreatment of ovary-intact female mice with the selective GRK2/3 inhibitor, Compound 101, made females equally sensitive to norBNI as males. Prior observations suggested that in vivo treatment with norBNI does not produce long-lasting inhibition of KOR regulation of dopamine release in the nucleus accumbens. We assessed the persistence of norBNI receptor inactivation in subcellular compartments. Fast-scan cyclic voltammetry recordings confirmed that presynaptic inhibition of dopamine release by the KOR agonist U69,593 was not blocked by in vivo pretreatment with norBNI under conditions that prevented KOR-mediated aversion and analgesia. We employed a novel in vivo proxy sensor of KOR activation, adenovirus associated double floxed inverted-HyPerRed, and demonstrated that KOR activation stimulates cJun kinase-dependent reactive oxygen species (ROS) production in somatic regions of ventral tegmental area dopamine neurons, but did not activate ROS production in dopamine terminals. The compartment selective action helps explain how dopamine somatic, but not terminally expressed, KORs are inactivated by norBNI. These results further elucidate molecular signaling mechanisms mediating receptor-inactivating KOR antagonist action and advance medication development for this novel class of stress-resilience medications.

\section{SIGNIFICANCE STATEMENT}

Kappa opioid receptor (KOR) antagonists are being developed as novel proresilience therapeutics for the treatment of mood and substance use disorders. This study showed that the longacting KOR antagonists are affected by both the sex of the animal and the subcellular compartment in which the receptor is expressed.

\section{Introduction}

Prolonged or severe behavioral stress exposure increases risk of mood and substance use disorders; (Kessler, 1997; Gold et al., 1998; Koob, 2008) . The release of endogenous opioid dynorphin peptides throughout the brain contributes to these adverse behavioral effects (Ehrich et al., 2015). For this reason, researchers have explored using kappa opioid antagonists as antidepressants and antiaddiction therapeutics in both preclinical research and human clinical trials (Carroll and Carlezon, 2013; Buda et al., 2015; Lowe et al., 2015; Carlezon and Krystal, 2016; Chavkin et al., 2019).

This research was supported by the National Institutes of Health National Institute of Drug Abuse [Grants RO1-DA030074, T32-DA07278, and P30DA048736] and National Institute of Mental Health [Grant T32-NS099578].

https://doi.org/10.1124/molpharm.120.000124.
Three different forms of kappa opioid receptor (KOR) antagonists have been identified: nonselective (e.g., buprenorphine and naltrexone) (Leander, 1988), selective long-acting receptor-inactivating compounds [e.g., norbinaltorphimine (norBNI) and JDtic] (Bruchas et al., 2007; Melief et al., 2011), and selective competitive antagonists (e.g., LY2456302 and BTRX-140) (Rorick-Kehn et al., 2014; Guerrero et al., 2019). There are theoretical advantages and disadvantages to each antagonist type, and it has yet to be determined which avenue is best to pursue for clinical development. The advantages of receptor-inactivating compounds include the ability to produce a stable effect with less concerns about patient compliance; however, several observations about their mechanism must be resolved before moving forward with the development of this class of medications.

ABBREVIATIONS: AAV-DIO, adenovirus associated double floxed inverted; aCSF, artificial cerebrospinal fluid; $\beta$-CNA, $\beta$-chlornaltrexamine; CMPD101, Compound 101, 3-[[[4-methyl-5-(4-pyridinyl)-4H-1,2,4-triazol-3-yl]methyl]amino]- $N$-[[2-(trifluoromethyl)phenyl]methyl]benzamide; DAT, dopamine transporter; GIRK, G protein-coupled inwardly rectifying potassium channel; GRK, G protein receptor kinase; JNK, cJun kinase; KOR, kappa opioid receptor; MAPK, mitogen-activated protein kinase; NAc, nucleus accumbens; norBNI, norbinaltorphimine; ROS, reactive oxygen species; VTA, ventral tegmental area. 
A recent study showed that there is a sex difference in cJun kinase (JNK) activation by norBNI in C57BL6-J mice (LamanMaharg et al., 2018). This work also demonstrated that in female C57BL6-J mice, pretreatment with norBNI does not reduce immobility in the forced swim test, in contrast to its effects in males. In addition to published concerns about effectiveness in female mice, we also noted that norBNI was not persistently antagonizing KOR inhibition of dopamine release when used in in vitro voltammetry assays of dopamine release (unpublished data). To understand and resolve these issues, we measured sex differences in response to norBNI and clarified the mechanisms responsible for its long-lasting effects on KOR function (Abraham et al., 2018).

The prototypical receptor-inactivating KOR antagonist norBNI has a long duration of action in vivo with effects lasting 14-21 days, but the drug does not persistently or covalently bind to the receptor (Smith et al., 1990; Horan et al., 1992; Butelman et al., 1993). Instead, norBNI has been demonstrated to disrupt KOR signaling by selectively activating a JNK signaling cascade which activates the phospholipase PRDX6 and subsequently stimulates the generation of reactive oxygen species (ROS) through an NADPH-oxidase mechanism (Bruchas et al., 2007; Fisher, 2011; Schattauer et al., 2017a). Local ROS production oxidizes the $\mathrm{G} \alpha_{\mathrm{i}}$ subunit at a critical cysteine palmitoylation site, disrupts $G$ protein-receptor interaction, and thus prevents agonistdependent guanine nucleotide exchange (Schattauer et al., 2017a). This KOR-inactivating process can be blocked by inhibitors of JNK or the phospholipase A2 activity of PRDX6 and can be detected with ROS sensors, including the genetically encoded indicator HyPerRed fluorescent protein indicator, which sensitively reports production of hydrogen peroxide (Schattauer et al., 2017a, 2019). ROS-dependent inactivation of KOR can be produced by administering a single high dose of norBNI or by administering repeated low doses of norBNI (Chavkin et al., 2019). This action is due to collateral agonist activity, an effect wherein a compound acts as an antagonist by selectively activating a subcomponent of receptor signaling, in turn inactivating subsequent signaling at that receptor (Kenakin, 2005; Bruchas et al., 2007). NorBNI's collateral agonist activity led us to hypothesize that the long-lasting effect is likely sensitive to sex hormone regulation and may be subject to signaling differences between different cell types and subcellular compartments.

In this study, we explored the constraints of norBNI's antagonist activity and assessed the persistence and subcellular localization of JNK-ROS-mediated receptor inactivation. We confirmed that norBNI is not a consistently effective long-acting antagonist in female mice, nor does it consistently increase phospho-JNK in female mice. We found that its phosphorylation of JNK and long-acting antagonist activity can be restored with the $\mathrm{G}$ protein receptor kinase (GRK) 2/3 inhibitor 3-[[[4-methyl-5-(4-pyridinyl)-4H-1,2,4-triazol-3-yl] methyl]amino]- $N$-[[2-(trifluoromethyl)phenyl]methyl]benzamide, Compound 101 (CMPD101), and that repeated, low doses of norBNI produced long-lasting antagonist effects in female mice. We also demonstrated that norBNI was not an effective long-acting antagonist at ventral tegmental area (VTA) dopamine terminals but did block KOR activation in VTA cell bodies. KOR-activated potassium [G protein-coupled inwardly rectifying potassium channel (GIRK)] currents in VTA dopamine neurons were inhibited 1 week after norBNI injection. Consistent with prior mechanistic studies of receptor inactivation, we found that KOR activation of ROS was evident in VTA dopamine cell bodies but not in the axons and terminals of dopamine neurons. These findings indicate that the pharmacological actions of norBNI depend on sex and cellular site of action.

\section{Methods}

Animals. Drug- and procedure-naïve C57BL/6-J mice (adult, male 20-30 g, female 17-25 g; bred for multiple generations after sourcing from Jackson Laboratories, Bar Harbor, ME) were group housed on a 12-hour light/dark cycle with food and water ad libitum. Animal procedures were approved by the Animal Care and Use Committee of the University of Washington and conform to the guidelines on the care and use of animals promulgated by the National Institutes of Health. Mice expressing Cre recombinase under the control of the endogenous dopamine transporter (DAT) locus containing an internal ribosome entry site (IRES) (Slc6a3 $3^{\text {IRES- }}$ Cre or DAT-IRES-Cre) were used for viral injections (Zhuang et al., 2005).

Drugs. U69,593 ((+)-(5 $\alpha, 7 \alpha, 8 \beta)-N$-methyl- $N$-[7-(1-pyrrolidinyl)-1-oxaspiro[4.5]dec-8-yl]-benzeneacetamide) (NIDA Drug Supply) was dissolved in solvent (DMSO) to $1 \mathrm{mM}$ stocks and stored at $-20^{\circ} \mathrm{C}$ for up to 1 month. $\beta$-chlornaltrexamine dihydrochloride ( $\beta$-CNA) (Sigma-Aldrich, St. Louis, MO) was dissolved $1 \mu \mathrm{g} / \mu \mathrm{l}$ in saline and stored at $-20^{\circ} \mathrm{C}$ for up to $1 \mathrm{month}$. U50,488 [2-(3,4-dichlorophenyl)- $N$-methyl- $N$-[( $1 R, 2 R)$-2-pyrrolidin-1-ylcyclohexyl]acetamide, NIDA Drug Supply] was dissolved in $1 \mathrm{mg} / \mathrm{ml}$ saline prior to intraperitoneal injection to $10 \mathrm{mg} / \mathrm{kg}$ for tail flick. norBNI (NIDA Drug Supply) was dissolved $1 \mathrm{mg} / \mathrm{ml}$ in saline prior to intraperitoneal injection unless stated otherwise. CMPD101 (Tocris, Bristol, United Kingdom) was dissolved at $1.5 \mathrm{mg} / \mathrm{ml}$ in $10 \%$ ethanol $/ 10 \%$ cremophor $/ 80 \%$ saline prior to intraperitoneal injections. CMPD101 and norBNI were delivered in intraperitoneal injections of $10 \mathrm{ml} / 1 \mathrm{~kg}$ of body weight to doses of 15 and $10 \mathrm{mg} / \mathrm{kg}$, respectively. Nalfurafine hydrochloride [(2E)$N$-[(5 $\alpha, 6 \beta)$-17-(cyclopropylmethyl)-3,14-dihydroxy-4,5-epoxymorphinan-6-yl]-3-(3-furyl)- $N$ methylacrylamide] (NIDA Drug Supply) was dissolved in sterile water at $100 \mu \mathrm{M}$ and stored at $-20^{\circ} \mathrm{C}$.

Behavioral Assays. Female mice were tested for latency (in seconds) to withdraw tail (flick) from $52.5^{\circ} \mathrm{C}$ water to assess antinociceptive effects of KOR activation (Bruchas et al., 2007). Mice were tested for basal latency to flick and treated with CMPD101 (15 mg/kg, i.p.), then tested 30 minutes later and treated with $\mathrm{U} 50,488$ (10 $\mathrm{mg} / \mathrm{kg}$, i.p.) and retested for latency to flick 30 minutes later. For repeated low-dose norBNI pretreatment, female mice received one injection of norBNI ( $1 \mathrm{mg} / \mathrm{kg}$, i.p.) or an equivalent volume of saline daily for 7 days prior to the tail withdrawal assay. For CMPD101 and norBNI pretreatment, female mice received CMPD101 (15 $\mathrm{mg} / \mathrm{kg}$, i.p.) and 30 minutes later, received norBNI $(10 \mathrm{mg} / \mathrm{kg}$, i.p.) or an equivalent volume of vehicle or saline, respectively, 7 days prior to the tail withdrawal assay. Estrous states of female mice were determined as described (Byers et al., 2012).

Stereotaxic Surgery (Intracerebro-Ventricular). Mice were anesthetized with isoflurane and mounted on a model 1900 stereotaxic alignment system (David Kopf Instruments, Tujunga, CA). $\beta$-CNA was loaded into a Hamilton syringe and 
delivered at a rate of $200 \mathrm{nl} / \mathrm{min}$ into the lateral ventricles [coordinates: anterior/posterior $(\mathrm{A} / \mathrm{P})+0.3$, medial/latereal $(\mathrm{M} / \mathrm{L})+0.8$, dorsal/ventral $(\mathrm{D} / \mathrm{V})-3.0$ or $\mathrm{A} / \mathrm{P}-0.5, \mathrm{M} / \mathrm{L}+1.0$, $\mathrm{D} / \mathrm{V}$-2.5] (Franklin and Paxinos, 2008). Two coordinates were used to avoid excess bleeding because of divergent location of skull sutures. An adenovirus associated double floxed inverted (AAV-DIO) virus was generated containing the genetically encoded ROS sensor HyPerRed (Ermakova et al., 2014; Schattauer et al., 2019). AAV-DIO HyPerRed virus was injected into the VTA of DAT-IRES-Cre heterozygous mouse (coordinates: $\mathrm{A} / \mathrm{P}-3.3, \mathrm{M} / \mathrm{L}+/-0.5, \mathrm{D} / \mathrm{V}-4.4$ ) so that the HyPerRed sensor would be expressed exclusively in dopamine neurons expressing Cre recombinase.

Fast-Scan Cyclic Voltammetry. Mice were decapitated, and the head was placed in preoxygenated, cold modified artificial cerebrospinal fluid (aCSF) (248 mM sucrose was substituted for $\mathrm{NaCl}$ ). The brain was removed, and $250 \mu \mathrm{m}$ coronal slices containing nucleus accumbens were prepared (model VT-1000X; Leica, Wetzlar, Germany). Nucleus accumbens slices were transferred to standard oxygenated aCSF (124 mM NaCl, $2.5 \mathrm{mM} \mathrm{KCl,} 1.25 \mathrm{mM} 12 \mathrm{NaH}_{2} \mathrm{PO}_{4}, 1.25 \mathrm{mM}$ $\mathrm{MgSO}_{4}, 2 \mathrm{mM} \mathrm{CaCl}_{2}, 10 \mathrm{mM}$ dextrose, $25 \mathrm{mM} \mathrm{NaHCO}_{3}$ ) and incubated for 1 hour at $37^{\circ} \mathrm{C}$, then held at room temperature before recordings. Slices were placed in a recording chamber, and perfused with oxygenated aCSF at $31-33^{\circ} \mathrm{C}$ throughout recording. Carbon-fiber working electrodes were fabricated as described (Clark et al., 2010; Lemos et al., 2012), hand-cut to 150-200 $\mu \mathrm{m}$ past the capillary tip. A single electric pulse (120-200 $\mu \mathrm{A}, 2$ millisecond per phase) was applied to a parallel bipolar stimulating electrode to evoke dopamine release, and the potential at the working electrode was held at $-0.4 \mathrm{~V}$ versus $\mathrm{Ag} / \mathrm{AgCl}$, ramped to $+1.3 \mathrm{~V}$ and back to $-0.4 \mathrm{~V}$ at a rate of $10 \mathrm{~Hz}$. Baseline dopamine release was measured every 2 minutes for 20 minutes prior to measuring release in response to $100 \mathrm{nM}$ U69,593. Waveform generation, data acquisition, and analysis were carried out using two peripheral component interconnect multifunction data acquisition cards and software written in LabVIEW version 7.1 (National Instruments, Austin, TX) as previously described (Clark et al., 2010; Lemos et al., 2012). Responses in the last 8 minutes (four recordings) were averaged to calculate the U69,593 response.

Electrophysiology. Horizontal VTA slices were prepared using the $N$-methyl D-gluconate artifical cerebrospinal fluid and HEPES solutions previously described (Ting et al., 2014). To record VTA GIRK currents, the resistance of the electrodes was 3-7 M $\Omega$ when filled with an internal solution of (millimolars) K-gluconate $130, \mathrm{NaCl} 5, \mathrm{Na}$ phosphocreatine 10 , $\mathrm{MgCl}_{2}$ 1, EGTA 0.02, HEPES 10, MgATP 2, Na ${ }_{2}$ GTP 0.5, $0.1 \%$ Biocytin, $\mathrm{pH}$ 7.3. Whole cell voltage clamp recordings were performed on neurons in the VTA-expressing tdTomato reporter expressed only in DAT-expressing neurons. The cell was voltage clamped at $-60 \mathrm{mV}$ using an Axopatch 200B amplifier (Molecular Devices, Foster City, CA). Signals were digitized by a Digidata 1440 analog/digital (A/D) converter (Molecular Devices) and stored using pClamp 10.2 software (Molecular Devices). To record GIRK currents, once a cell was stably patched and basal physiology assessed, the slice was bathed in high potassium $\left(5.5 \mathrm{mM} \mathrm{K}^{+}\right)$aCSF to enhance the currents in the cells at hyperpolarized potentials. As expected, when the slice was incubated in high $\left[\mathrm{K}^{+}\right]$, the holding current increased, and inward rectification was more apparent. The membrane potentials of VTA neurons were subjected to a voltage ramp protocol in which they were brought from -120 to $-50 \mathrm{mV}$ over 10 seconds. After three stable ramp measurements (the average of three sweeps) were obtained, $\mathrm{U} 69,593(1 \mu \mathrm{M})$ was bath applied, and the slice was allowed to equilibrate for 3 minutes. Subsequently, a ramp measurement was taken after 12 minutes of U69,593 application, and the three sweeps were averaged. After U69,593 application and stable current responses, $\mathrm{BaCl}_{2}(100 \mu \mathrm{M})$ was added to distinguish $\mathrm{Ba}^{2+}$-sensitive GIRK currents.

Conductance was calculated as the slope of the currentvoltage (I-V) curve in response to a voltage ramp from -120 to $-50 \mathrm{mV}$. Maximal inward current was calculated as the average current in response to a $-115 \mathrm{mV}$ applied voltage.

HyPerRed Imaging and Analysis. VTA slices were prepared as described above for the slice recordings. Modified aCSF solution included $800 \mu \mathrm{M}$ thiourea and $400 \mu \mathrm{M}$ sodium ascorbate (Rice, 1999) to reduce cellular stress and keep basal ROS levels low. Agonist-induced ROS HyPerRed fluorescence was recorded on an upright fluorescent microscope (BX51WI; Olympus, Tokyo, Japan), with the fluorophore excited by CoolLED pE300 through the $20 \times$ objective at $555 \mathrm{~nm}$ and collected using an Hammamatsu ORCA-Flash4.0 V2 camera and HC Image Live software. Images were collected every 2 minutes with an exposure time of 100-500 millisecond and light-emiting diode (LED) intensity of $50 \%$. For nalfurafine experiments, 35 images were taken over 70 minutes. aCSF was washed on for 15 minutes, aCSF containing nalfurafine (100 nM) was washed on for 45 minutes, and $200 \mu \mathrm{M} \mathrm{H}_{2} \mathrm{O}_{2}$ was added for the final 10 minutes (images 31-35). For naloxone-nalfurafine experiments, 40 images were taken over 80 minutes to establish a secondary baseline of aCSF plus naloxone $(1 \mu \mathrm{M})$, prior to wash-on of aCSF with both naloxone and nalfurafine. $\Delta \mathrm{F} / \mathrm{F}$ was calculated as the current fluorescence minus the average fluorescence of the four images prior to nalfurafine ("baseline fluorescence"), divided by the baseline fluorescence. Inclusion criteria required that cells significantly increase $\Delta \mathrm{F} / \mathrm{F}$ at the end of experiment in response to $\mathrm{H}_{2} \mathrm{O}_{2}(100 \mu \mathrm{M})$ application. Due to mild bleaching over the course of the experiment, a "Baseline2" was calculated as the average of the two images prior to $\mathrm{H}_{2} \mathrm{O}_{2}$ wash on. Any image that did not show a fluorescence increase of at least $5 \%$ in response to $\mathrm{H}_{2} \mathrm{O}_{2}$ was excluded from this study, as in these cases we could not confirm functional protein expression or tissue viability.

Striatal Dissections for Phospho-JNK Western Blot. Mice were decapitated at the specified times after drug administration. Ventral striata were dissected and homogenized with a Dounce homogenizer on ice in mitogen-activated protein kinase (MAPK) lysis buffer composed of $50 \mathrm{mM}$ Tris$\mathrm{HCl}, 300 \mathrm{mM} \mathrm{NaCl}, 1 \mathrm{mM}$ EDTA, $1 \mathrm{mM} \mathrm{Na} \mathrm{VO}_{4}, 1 \mathrm{mM} \mathrm{NaF}$, $10 \%$ glycerol, $1 \%$ Triton $\mathrm{X}-100$, protease inhibitor cocktail (Sigma-Aldrich), and phosphatase inhibitor cocktail (Millipore, Burlington, MA). Samples were centrifuged 25 minutes at $30,000 \mathrm{~g}$ at $4^{\circ} \mathrm{C}$. Protein concentrations in supernatant were determined by bicinchoninic colorimetric assay (Thermo Fisher Scientific, Waltham, MA), mixed with $4 \times$ LDS buffer (10\% lithium dodecyl sulfate, $25 \%$ glycerol, $\mathrm{pH}$ 8.4; Thermo Fisher Scientific) supplemented with $8 \% \beta$-mercaptoethanol and stored at $-20^{\circ} \mathrm{C}$ until analysis by Western blot.

Western Blot for Phospho-JNK. Samples were loaded with $20 \mu \mathrm{g}$ of protein onto $10 \%$ Bis-Tris precast gels (Thermo 
Fisher Scientific) and run at $100 \mathrm{~V}$ for 2 hours. Blots were transferred to nitrocellulose (Thermo Fisher Scientific) for 1.5 hours at $30 \mathrm{~V}$. The nitrocellulose was blocked with $5 \%$ bovine serum albumin-tris-buffered saline (TBS) and Polysorbate 20 (Tween 20) (TBST) 1 hour at room temperature and stained overnight at $4^{\circ} \mathrm{C}$ with rabbit anti-phospho-JNK antibody (catalog number 9251, lot 27; Cell Signaling Technology, Danvers, MA) 1:1000 and mouse anti-actin antibody (AB8226, lot GR111289-6; Abcam, Cambridge, MA) 1:5000 in $5 \%$ bovine serum albumin-TBST. Blots were incubated in IRDye secondary antibody (catalog number 926-68070, lot C50721-05 and catalog number 926-32211, lot C506602-05; 1:15,000; LI-COR Biosciences, Lincoln, NE) in 1:1 Odyssey buffer (LI-COR Biosciences) and 5\% milk-TBST for 1 hour at room temperature and then scanned on the Odyssey IR Imaging System (LI-COR Biosciences). Band intensity with background subtraction was measured using Odyssey software (Image Studio Lite 5.2; LI-COR Biosciences). Phosphoprotein band intensity was normalized to or actin band intensity. Data were normalized to percentage of control vehicle treated and plotted using GraphPad Prism 8.2 (GraphPad Software, Inc., La Jolla, CA). Statistical significance $(P<$ 0.05 ) was determined by ANOVA followed by Sidák's post hoc test.

Experimental Design and Statistical Analysis. All of the studies described in this report were designed to test specific a priori hypotheses. Behavioral and imaging data were collected and analyzed with the investigator blind to treatment. Animal numbers were as follows: tail flick, male $n=7$ per group; CMPD101-norBNI, $n=4$ to 5 female mice per group; repeated, $n=7$ female mice per group; norBNI voltammetry, $n=5$ to 6 animals per group; $\beta$-CNA voltammetry, $n=4-6$ animals per group; electrophysiology, $n=7$ to 8 animals, $7-10$ cells per group; HyPerRed (four animals per group). Sample sizes were estimated with power analysis prior to assays and adapted when effect size

\section{Tail Flick Analgesia}

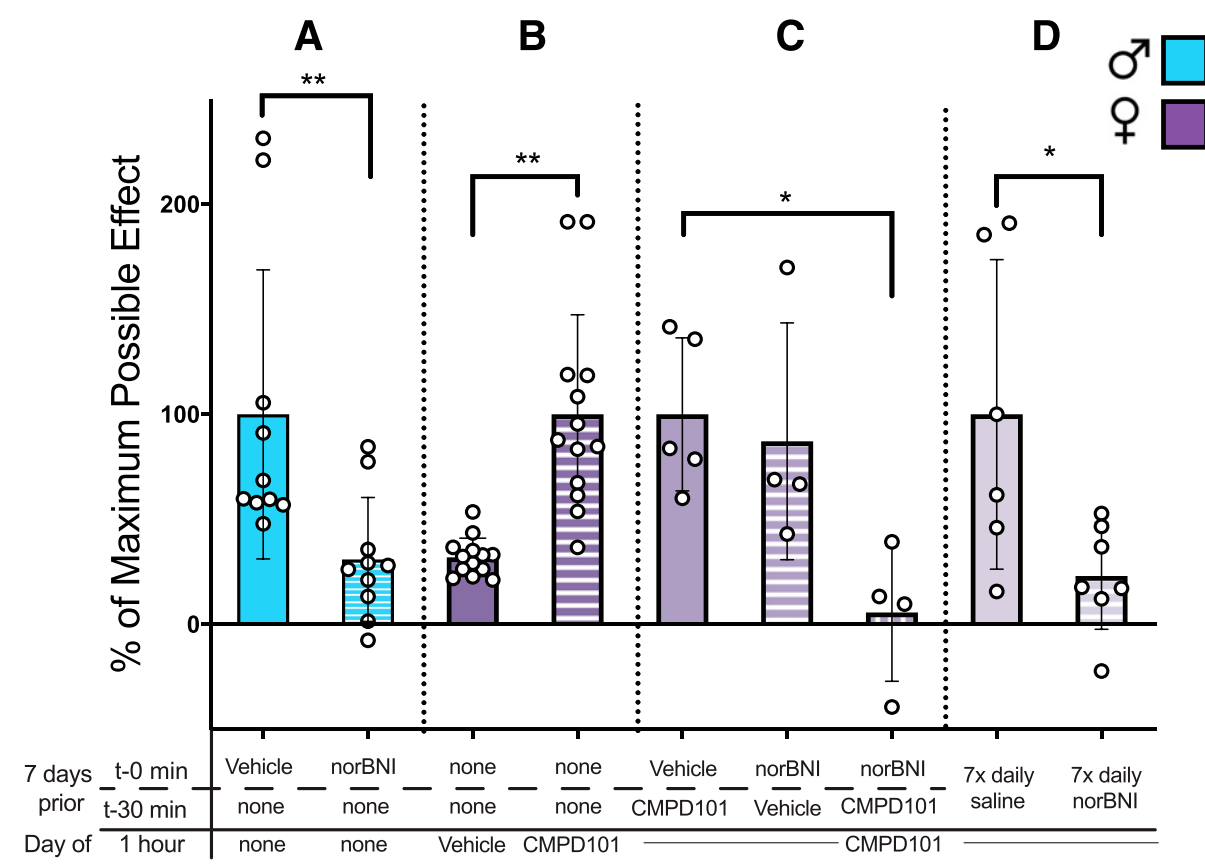

E

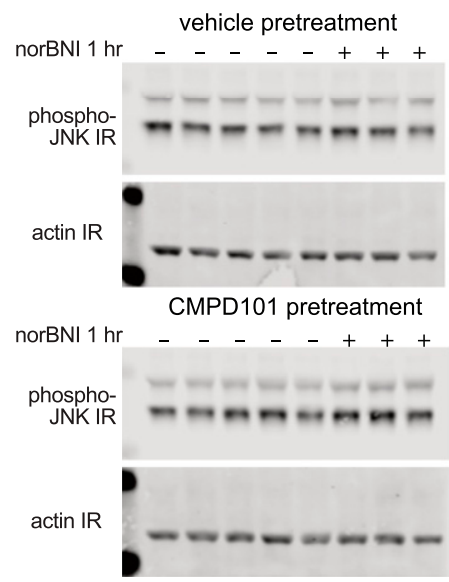

$\mathbf{F}$

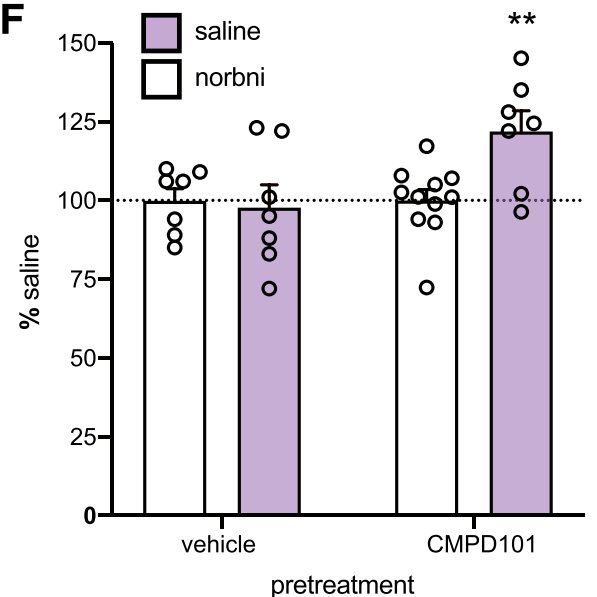

Fig. 1. Long-acting norBNI antagonism in females is effective if given in repeated doses or after CMPD101. Note: all groups are independent studies with unique control group; each experiment is separated by a dashed line. They are shown as maximum possible effect to compare across groups. Error bars of variability shown are S.D.s of the means. (A) Male mice were injected with either saline or $10 \mathrm{mg} / \mathrm{kg}$ norBNI (i.p.). One week later they were injected with $10 \mathrm{mg} / \mathrm{kg}$ U50,488 and tested for a shift in tail withdrawal latency after immersion in $52.5^{\circ} \mathrm{C}$ water. Male mice pretreated with norBNI did not show a significant increase in tail flick latency, but those pretreated with saline did. (Unpaired two-tailed $t$ test, onetailed: $\mathrm{t}_{2.916,18} P=0.0092$.) (B) Female mice did not show an increased latency to flick after U50,488 treatment (data reprinted from Abraham et al., 2018 ) but did after pretreatment with CMPD101(15 mg/kg), U50,488. (C) One-week pretreatment with either CMPD101 alone or norBNI alone did not affect U50,488 increase in tail flick latency, but treating mice with CMPD101 prior to norBNI led to a long-acting block of the U50,488 increase in tail flick latency (one-way ANOVA F $=5.316$, $P=0.0242$; Tukey's post hoc CMPD101-vehicle vs. CMPD101-norBNI $P=0.0215$ ). (D) Female mice treated with repeated saline injections showed an increase in tail flick latency to CMPD101 plus U50,488, but those treated with repeated norBNI doses did not. (Unpaired twotailed $t$ test: $\mathrm{t}_{2.607,11} P=0.0204$.) (Each group separated by dotted lines was normalized to the maximum possible effect within the group. Error bars indicate S.D.. All groups were compared using a one-way ANOVA $P<0.05$; post hoc Bonferonni $* P<0.05$; ** $P<0.01$ ). (E) Western blot immunoreactivity to phosphoJNK and actin control in striatal amples taken from mice pretreated with either CMPD101 or vehicle then given vehicle or norBNI, 60 minutes prior to decapitation. (F) Quantitation of Western blot immunoreactivity (IR) demonstrating that norBNI caused a significant increase in striatal phospho-JNK in female mice pretreated with CMPD101, but not in mice pretreated with saline (two-way ANOVA with Sidák post hoc). 
was an order of magnitude outside of our estimations. This occurred for the HyPerRed experiment, as it was a novel technique in which we expected lower signal to noise; however, we saw a substantial signal over baseline and 10 -fold higher $\Delta \mathrm{F} / \mathrm{F}$ values than we predicted from pilot studies in cell culture. Due to sex-dependent effects in norBNI action (described in Fig. 1), experimental animals were all male in Figures 2-4. Data were analyzed with Prism 7 software (GraphPad). Group differences were determined using $t$ tests, ANOVA, or repeated-measures ANOVA as described in the Results. Post hoc comparisons were analyzed with Tukey's or Šidák's test. For all statistical tests, $\alpha$ was set to 0.05 .

\section{Results}

Duration of Antinociceptive Action of norBNI in the Tail-Withdrawal Assay. Male mice treated with $10 \mathrm{mg} / \mathrm{kg}$ U50,488 show a significant increase in latency to withdraw their tails from $52.5^{\circ} \mathrm{C}$ water, which was normalized to $100 \%$ of maximum possible effect. As previously reported, a single $(10 \mathrm{mg} / \mathrm{kg}$, i.p.) injection of norBNI 7 days prior to
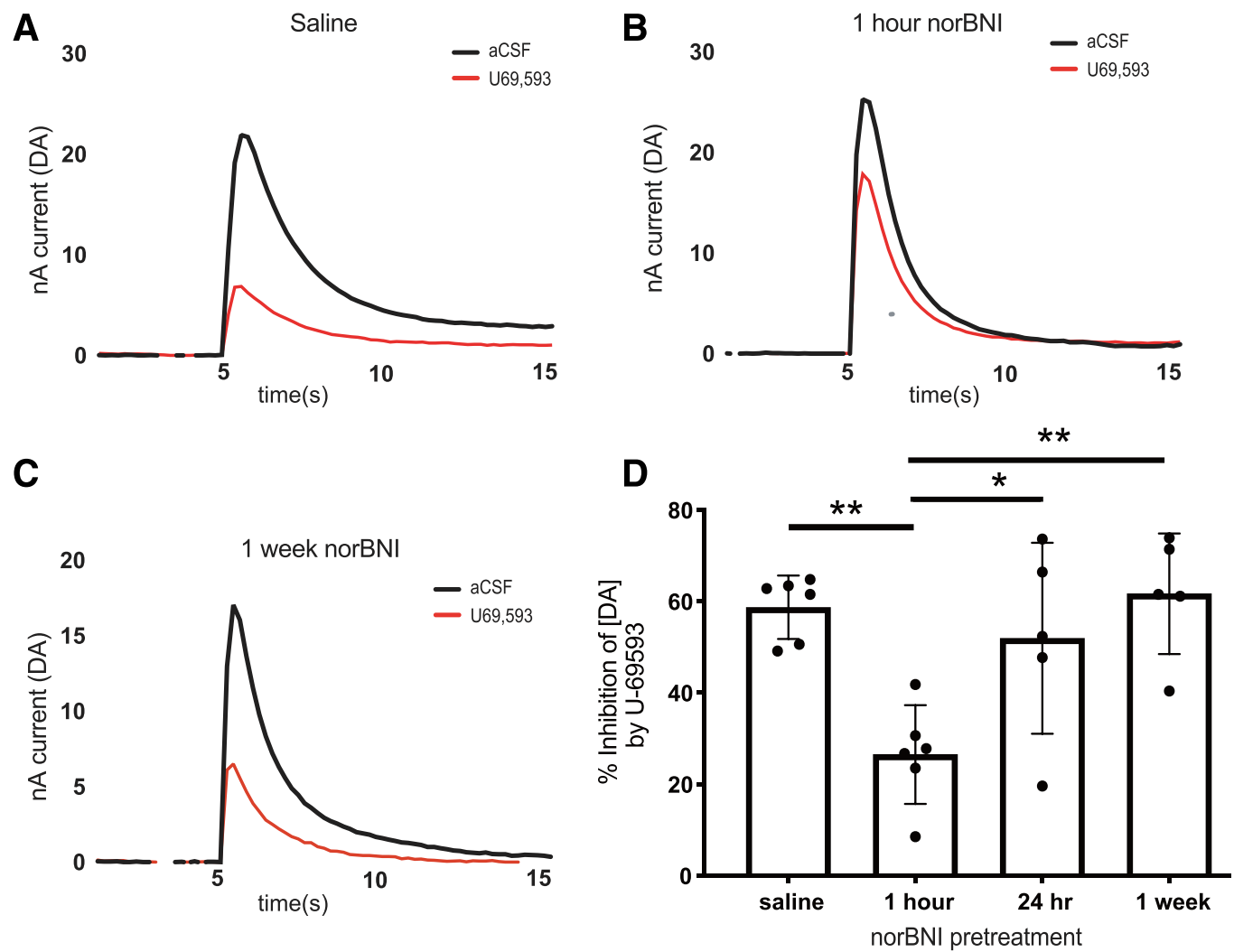

$\mathbf{E}$

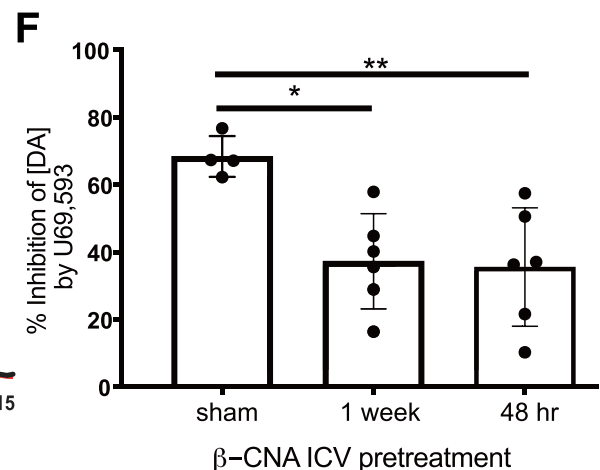

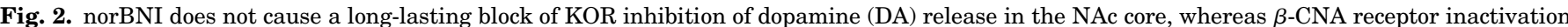

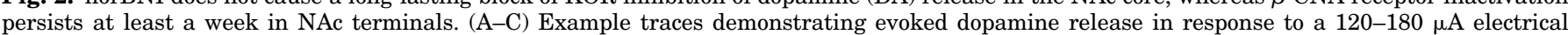

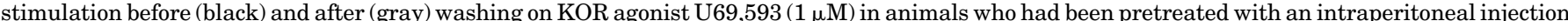

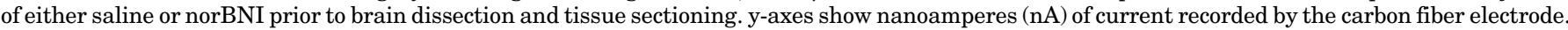

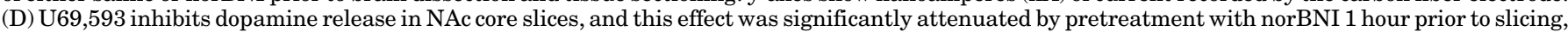

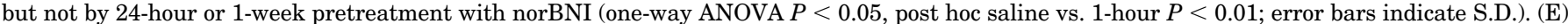

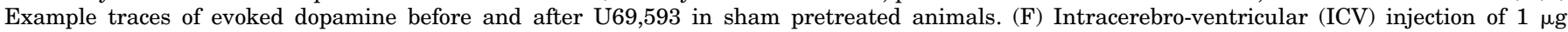

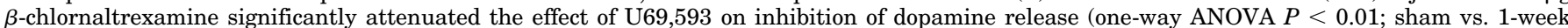
$P<0.05$, sham vs. 48 -hour $P<0.01$; error bars indicate S.D.). ${ }^{*} \mathrm{P}<0.05$; $* * \mathrm{P}<0.01$. 

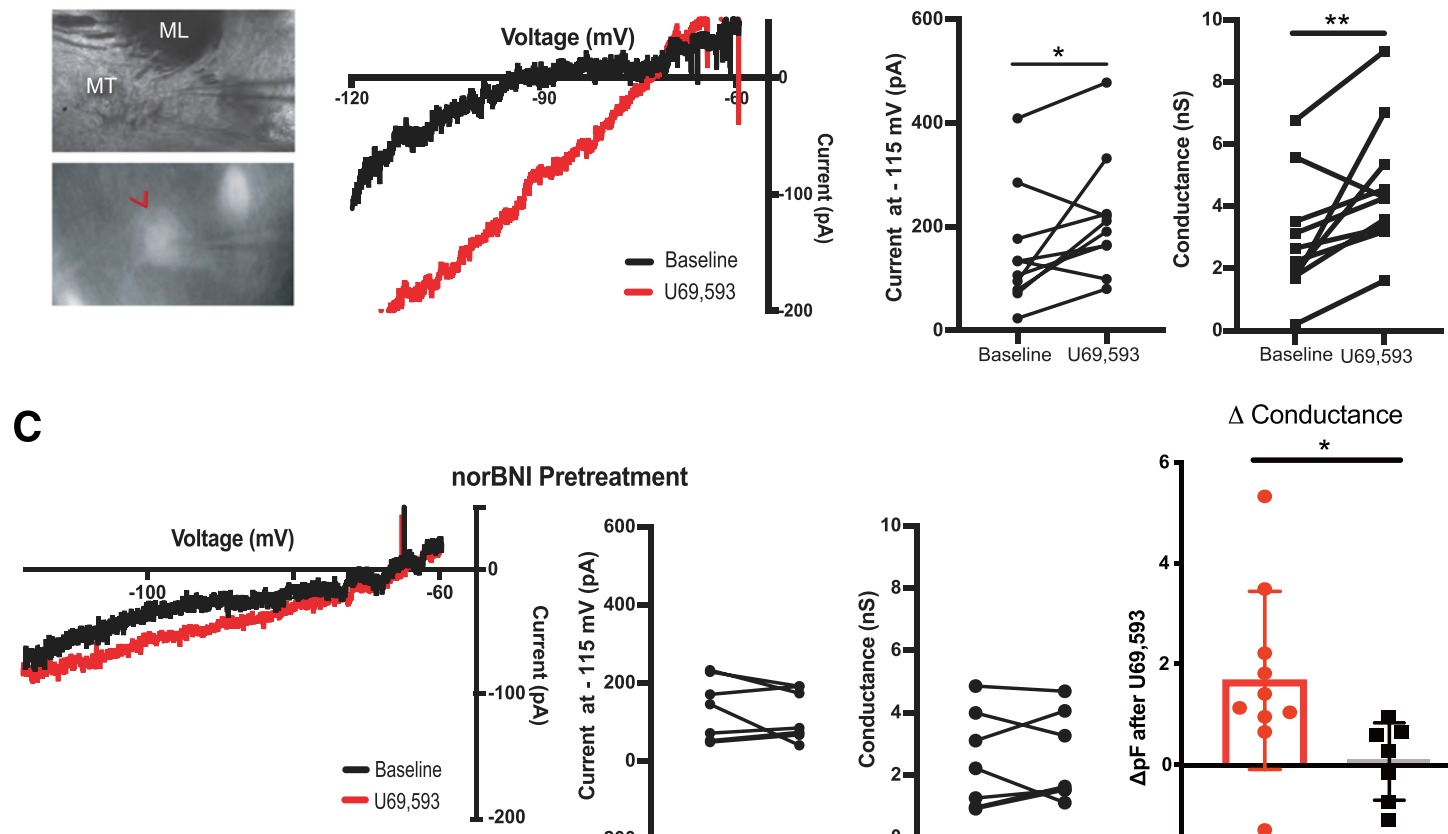

orBNI Pretreatment
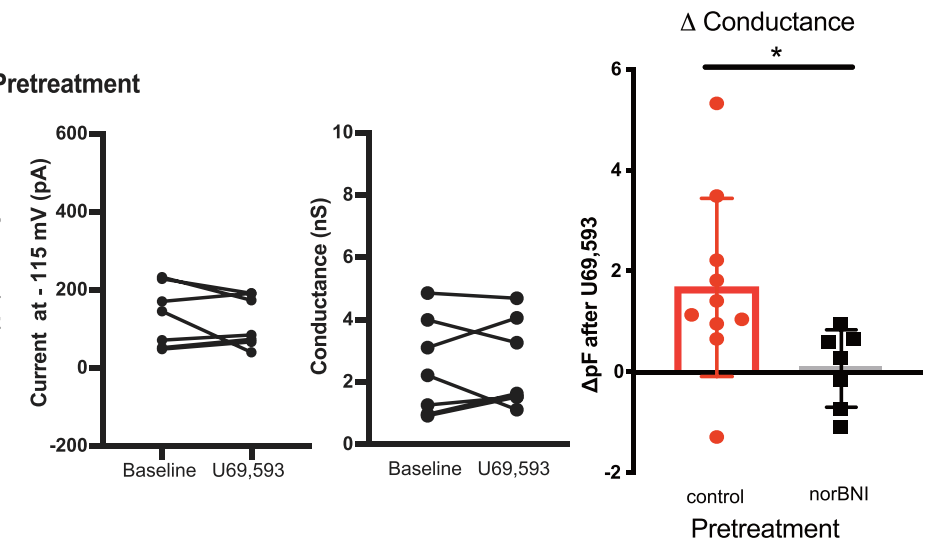

Fig. 3. KOR agonist U69,593 activates a GIRK current in VTA dopamine neurons that can be blocked by norBNI pretreatment. (A) Fluorescent cells in the VTA DAT-IRES-Cre Flox-tdTomato mice were patched and held at $-60 \mathrm{mV}$. GIRK currents were elicited by subjecting the cells to a voltage ramp from -120 to $-50 \mathrm{mV}$. Abbreviations ML is medial lemniscus and MT is medial terminal nucleus of the accessory optic tract; both of these anatomical landmarks define the borders of the VTA. (B) GIRK current at baseline and in response to $1 \mu \mathrm{M}$ U69,593: example trace, current at -115 mV, and conductance. Treatment with the KOR agonist significantly increased GIRK currents (paired two-tailed $t$ test, $P<0.05$ ) and conductance as calculated by the slope of the line from -120 to $-50 \mathrm{mV}$ (paired two-tailed $t$ test, $P<0.05$ ). (C) GIRK currents as measured at baseline and after U69,593 from animals pretreated with norBNI; example trace, current at $-115 \mathrm{mV}$, and conductance. (D) Peak current after U69,593 minus peak current at baseline denoted as " $\Delta \mathrm{pF}$ after U69,593" is significantly different in controls as compared with animals pretreated with norBNI. (Unpaired two-tailed $t$ test $* P<0.05$; $* * P<0.01$; error bars indicate S.D.).

analgesic testing blocked U50,488-mediated increase in tail flick latency in male mice (Fig. 1A) (unpaired two-tailed $t$ test: $\mathrm{t}_{2.916,18} P=0.0092$ ). In contrast to male mice, U50,488 alone did not significantly increase tail flick latency in female mice (Fig. 1B). As previously reported, the estrous state-dependent insensitivity to U50,488 effect is caused by estradiol-stimulated GRK2/3 signaling (Abraham et al., 2018). Pretreatment with the GRK2/3 inhibitor CMPD101 restored sensitivity to U50,488 in female mice (Fig. 1B). We predicted that, like with neutral KOR agonist, norBNI would not be long-acting in female mice due to its action as a biased KOR agonist stimulating the phosphorylation of JNK. Although CMPD101 given just prior to U50,488 restores the effectiveness of the agonist, norBNI administered 1 week prior to CMPD101U50,488 treatment did not block KOR-mediated analgesia in female mice, indicating that there is also a sex difference in norBNI sensitivity (Fig. 1C). To test if estradiol-GRK2/3 signaling was also responsible for this sex difference, we administered CMPD101 prior to norBNI antagonist pretreatment 7 days before the tail flick assay. The analgesic effects of U50,488 were blocked in mice treated with CMPD101 and norBNI, but not in those female mice treated with norBNI alone (Fig. 1C). Neither CMPD101 alone nor norBNI alone blocked CMPD101-U50488 analgesia evident in female mice (one-way ANOVA F $=5.316, P=0.0242$; Tukey's post hoc CMPD101-vehicle vs. CMPD101-norBNI $P=0.0215$ ). These data suggest that, as we predicted, the estrogen-GRK2 mechanism responsible for sex differences in KOR agonist action previously identified (Abraham et al., 2018) also contributes to the sex differences in norBNI duration of action. Thus, estradiol-stimulated GRK2 sequestration of G $\beta \gamma$ likely disrupts norBNI activation of JNK, thereby disrupting receptor inactivation of KOR by norBNI-stimulated JNK production of ROS ( Schattauer et al., 2017a; Abraham et al., 2018).

Repeated Low Doses of norBNI Produce a Long-Lasting Antagonist Effect in Female Mice. The utility of a long-acting KOR antagonist in women that requires concomitant GRK2/3 inhibition is not practical from a compliance perspective. An alternative dosing strategy might circumvent that constraint. We hypothesized that if female mice were treated repeatedly with a low dose of norBNI, the cumulative effect of dosing over multiple days of their estrous cycle including during low-estradiol phases, might produce a longacting block of U50,488-mediated tail flick. This potentially safer low-dosing strategy was previously demonstrated to be effective in males (Chavkin et al., 2019).

Female mice were injected with norBNI ( $1 \mathrm{mg} / \mathrm{kg})$ or saline once per day for 7 days. We subjected these mice to CMPD101U50,488 tail flick 48 hours after the end of the week-long pretreatment. U50,488-induced analgesia was blocked by repeated norBNI, but not affected by repeated saline pretreatment (Fig. 1D). There was no significant interaction, but there was a trend toward an interaction and a significant effect of pretreatment and time (unpaired two-tailed $t$ test: $\mathrm{t}_{2.607,11} P=0.0204$ ). 
A

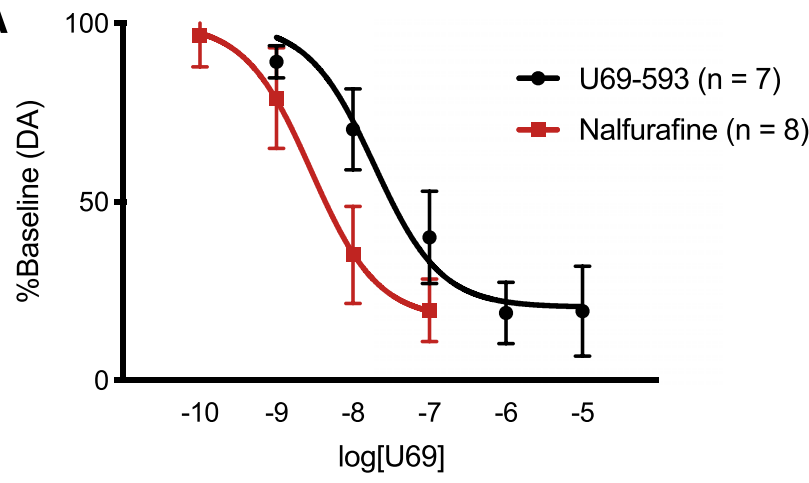

B

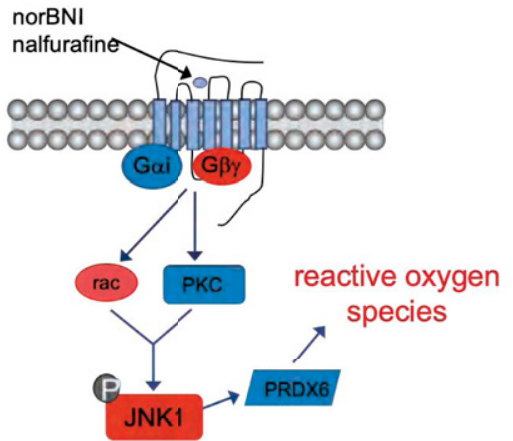

C
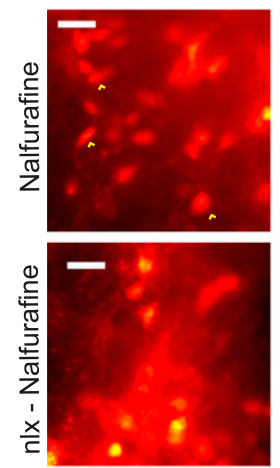

Before Drug
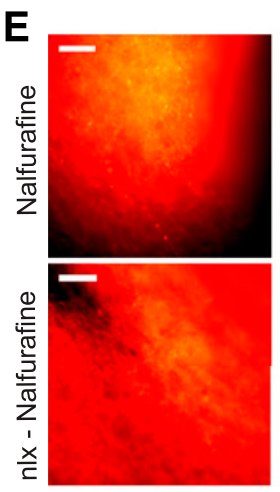

Before Drug
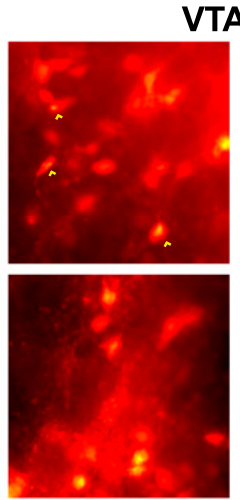

25 min Post Drug

TA HyPerRed in Dopamine Cell Bodies

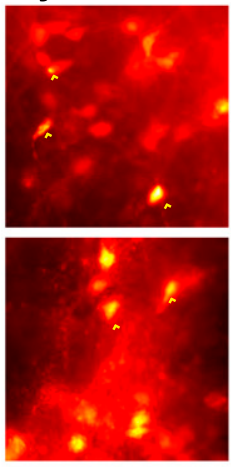

$200 \mathrm{uM} \mathrm{H} 2 \mathrm{O} 2$

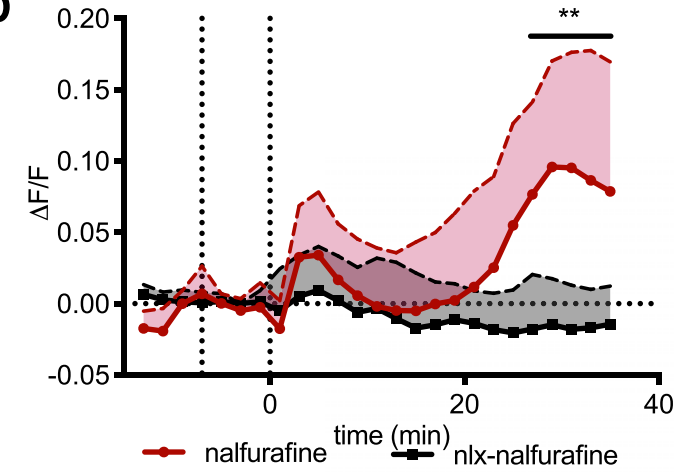

NAc HyPerRed in Dopamine Terminals
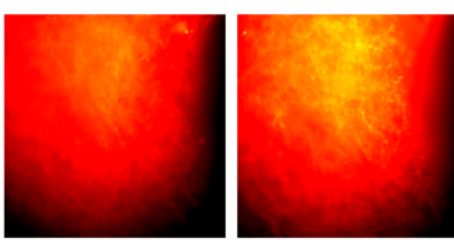

\section{$\mathbf{F}$}

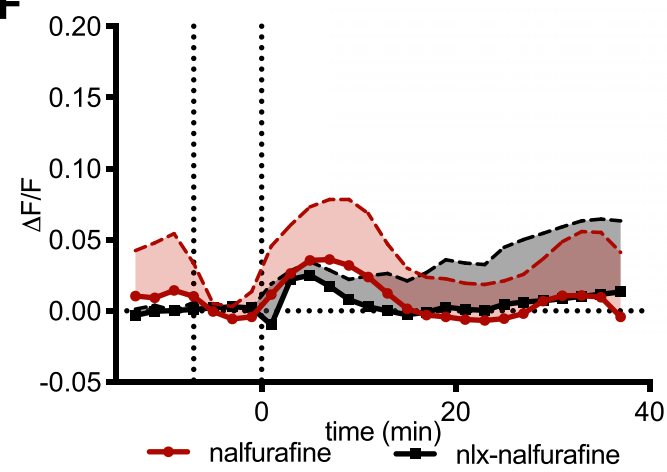

200 uM H2O2

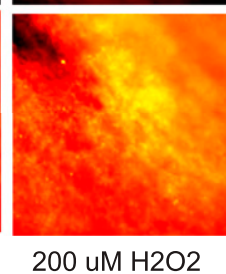

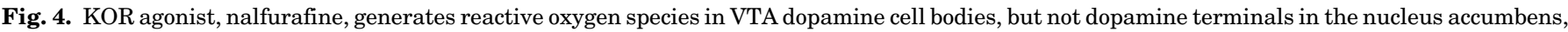

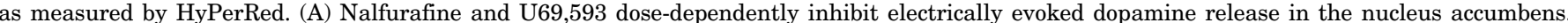

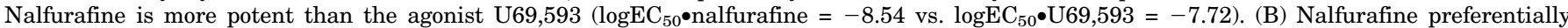

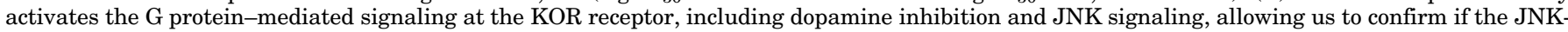

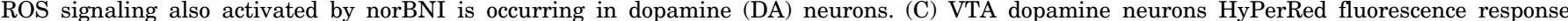

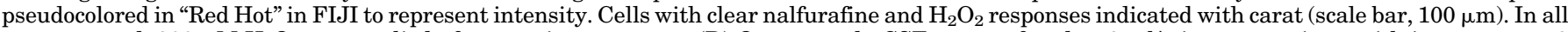

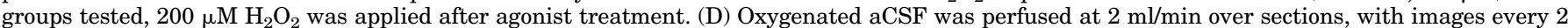

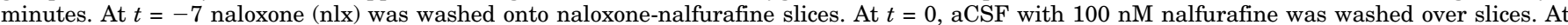

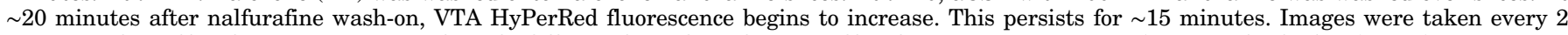

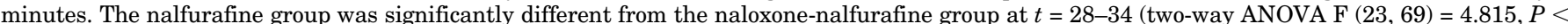

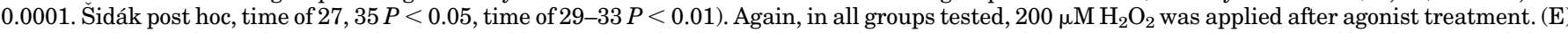

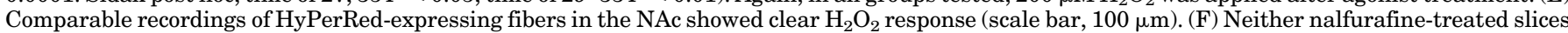
nor naloxone-nalfurafine-treated slices showed a significant response to nalfurafine (two-way ANOVA F $(25,150)=0.3309, P>0.9)$.

Increase in Phospho-JNK Detected in Female Mice Pretreated with CMPD101 Prior to norBNI, but Not in Female Mice Treated with norBNI in the Absence of CMPD101. Prior studies have demonstrated that, in male mice, norBNI stimulates phospho-JNK in the striatum, and that this phospho-JNK is necessary for the long-lasting effects of norBNI (Bruchas et al., 2007). We predicted that GRK2/3 inhibition by CMPD101 would be required to replicate this norBNI-mediated phospho-JNK in female mice, similarly to the CMPD101 pretreatment required to see the long-lasting block of tail flick described above. To test if the sex difference we see in norBNI action is due to estradiol-dependent shifts in 
G $\beta \gamma$ sequestration, we measured the phospho-JNK immunoreactivity with Western blot in striatal protein samples taken from mice given norBNI or saline with either a vehicle or CMPD101 pretreatment (Fig. 1, B and C). Mice were given vehicle ( $80 \%$ saline, $10 \%$ cremophor, $10 \%$ ethanol) 30 minutes prior to norBNI (10 mg/kg i.p. in saline) or saline. After an hour, we dissected their striata, isolated protein, and measured phospho-JNK using Western blot. The norBNI alone did not cause a consistent increase over vehicle in our preliminary data (Fig. 1, B and C). However, pretreatment with CMPD101 (15 mg/kg in $80 \%$ saline, $10 \%$ cremophor, $10 \%$ ethanol), prior to norBNI led to a significant increase over the CMPD101/ saline controls (Fig. 1, B and C) (two-way ANOVA: interaction $\mathrm{F}(1,28)=5.236, P=0.0299$; pretreatment $\mathrm{F}(1,28)=5.361, P=$ 0.0281 ; Šidák post hoc: saline condition $P=0.997$, CMPD101 pretreatment $P=0.0087$ )

Collectively, these data demonstrate that norBNI acts effectively as an antagonist against KOR-mediated analgesia in both male and female mice. However, in female mice, because high estradiol can make norBNI less effective, KOR inactivation is only evident either after pretreatment with CMPD101 or in mice repeatedly treated with low doses of norBNI. In conjunction with recently published data (Chavkin et al., 2019), these results indicate that repeated, low-dose norBNI treatment may be effective in both male and females. Due to this sex difference, the rest of the reported results assessing the constraints of norBNI's effectiveness in neuronal compartments were completed in male mice.

NorBNI Antagonism of KOR Inhibition Does Not Persist in Dopamine Terminals. KOR expression has been shown to be required on VTA dopamine neurons for conditioned place aversion to U50,488 (Ehrich et al., 2015). However, while studying the underlying mechanisms involved, we consistently found that in vivo pretreatment with norBNI did not have long-lasting effects on KOR regulated dopamine release as measured using slice ex vivo voltammetry. The discrepancy between norBNI's long-lasting effects on KOR-dependent aversion and its lack of long-lasting effect in vitro is surprising because the dominant theory rationalizes the KOR aversion as a consequence of presynaptic inhibition of dopamine release (Chefer et al., 2013).

Traditional kappa opioid receptor agonists are known to generate a robust inhibition of dopamine terminals in the nucleus accumbens (Di Chiara and Imperato, 1988). To systematically establish whether presynaptic inhibition can be blocked by norBNI, C57BL/6-J mice were injected with $10 \mathrm{mg} / \mathrm{kg}$ norBNI or an equivalent volume of saline 1 week, 24 hours, or 1 hour prior to brain dissection and tissue sectioning (Fig. 2, A-D). We predicted that if norBNI was a long-lasting antagonist, inhibition of U50,488 effects on dopamine release would be evident 1 hour after in vivo administration and persist for 1 week. In contrast, we found that NorBNI acted as an effective antagonist in animals sectioned 1 hour after intraperitoneal injection of norBNI, but neither 24-hour nor 1-week pretreatment with norBNI was effective at blocking the U50,488 effects on evoked dopamine release (one-way ANOVA $\mathrm{F}=8.17, P=0.0012$, Tukey's post hoc saline vs. 1 -hour $P=0.0031$, saline vs. 24 hour $P=0.8396$, saline vs. 1 -week $P=0.9381$ ). These results confirm that norBNI could penetrate to the ventral striatum and acutely block KOR but did not produce long-lasting receptor inactivation at VTA dopamine terminals.
Covalent Inactivation of KOR by $\beta$-Chlornaltrexamine Effectively Blocked KOR Signaling for up to a Week. To test if a higher rate of receptor recycling in the terminals as compared with cell bodies explained the shortened duration of action of norBNI in dopamine terminals, we used $\beta$-CNA to block opioid signaling. $\beta$-CNA is a nitrogen mustard analog of naltrexone that covalently binds to the ligand binding site in the opioid receptor to irreversibly prevent agonist occupation (Schoenecker et al., 1987). Intracerebro-ventricular injection of $1 \mu \mathrm{g} \beta$-CNA significantly blocked KOR agonist-mediated inhibition of dopamine release from dopamine terminals after either 48 hours or 1 week after injection (Fig. 2, E and F) (oneway ANOVA F $=7.545, P=0.0067$, Tukey's post hoc sham vs. 48 hour $P=0.009$, sham vs. 1 -week $P=0.0129$ ). Because $\beta$-CNA effectively blocked KOR signaling a week after treatment, faster receptor turnover in dopamine nerve terminals cannot explain the lack of long-lasting norBNI antagonism.

NorBNI Antagonism of U69,593-Mediated Activation of GIRK Currents Persists up to a Week in Dopamine Cell Bodies. The lack of long-lasting norBNI effects in dopamine terminals raises the possibility that the cellular machinery for long-lasting inactivation by norBNI is not expressed by dopamine neurons. To address this, as well as any concerns that slice preparation itself disrupts the norBNI receptor inactivation, we tested whether norBNI produced a long-lasting inhibition of the physiologic responses to KOR activation evident in the cell bodies of dopamine neurons. KOR agonists, like other Gi/o-coupled receptors can acutely reduce the excitability in the somatodendritic compartment by increasing conductance of GIRK channels, and norBNI has been previously shown to acutely block this response in VTA dopamine neurons (Margolis et al., 2006).

We injected mice with $10 \mathrm{mg} / \mathrm{kg}$ norBNI or saline 1 week prior to in vitro electrophysiological recording. Dopamine neurons, identified using tdTomato reporter expression in DAT-IRES-Cre mice (Fig. 3A), consistently showed an increase in the BaCl-sensitive GIRK current and membrane conductance after in vitro application of $1 \mu \mathrm{M}$ U69,593 (Fig. 3B) (paired two-tailed $t$ test, current at $-115 \mathrm{mV}: \mathrm{t}_{2.4,9}$, $P=0.0397$, conductance: $\mathrm{t}_{3,9}, P=0.015 ; n=8$ animals, 10 cells). However, cells from mice pretreated with norBNI 1 week prior to brain dissection showed no significant increase in GIRK current or conductance in response to $1 \mu \mathrm{M}$ U69,593 (Fig. 3C) (paired two-tailed $t$ test, current at $-115 \mathrm{mV}: \mathrm{t}_{0.962,6}, P=$ 0.374 , conductance: $\mathrm{t}_{0.242,6}, P=0.817 ; n=7$ animals, seven cells). These data show that norBNI does block KOR-mediated facilitation of somatic GIRK currents in VTA dopamine neurons for at least a week after injection. In most VTA dopamine neurons we patched (primarily in the lateral aspect of the VTA and labeled with DAT-Cre TdTomato fluorescent reporter), we showed potentiated GIRK current in response to $\mathrm{KOR}$ agonists. Because long-lasting KOR inactivation is a consequence of JNK/PRDX6-mediated ROS generation (Schattauer et al., 2017a), these results suggest that norBNI may effectively activate this signaling cascade in the cell bodies but not in terminals of VTA dopamine neurons. The local effects of norBNI have not previously been reported and suggest that neither the kappa receptors nor the signal transduction mediators can effectively migrate between somatic and terminal cellular compartments.

We recently developed a virus containing a sensor for $\mathrm{H}_{2} \mathrm{O}_{2}$ that acts as a proxy for JNK-ROS activation by KOR 
(Schattauer et al., 2017a, 2019). To further delineate the differences in KOR signal transduction in dopamine neuron cell bodies and terminals, and determine if differences in ROS were responsible for the duration of antagonist action, we measured the ROS generation stimulated by KOR agonist activity. We used the functionally selective KOR agonist nalfurafine (Schattauer et al., 2017b). Nalfurafine is a better reagent to address these mechanistic questions because it is a KOR agonist that does not effectively activate p38 MAPK, which inhibits ROS generation (Schattauer et al., 2019). We have observed that it stimulates ROS to a greater extent than $\mathrm{U} 69,593$ and more rapidly than norBNI. As shown in Figure 4A, nalfurafine potently inhibited the release of dopamine with a logEC50 of -8.54 (95\% CI -8.72 to -8.33 ) (equivalent to $2.9 \mathrm{nM}$ ). Nalfurafine was approximately 10 -fold more potent than U69,593, with comparable efficacy (Fig. 4A). To visualize neuronal ROS dynamics (Fig. 4B), we recorded fluorescence emitted from the virally encoded ROS indicator, AAV-DIO-HyPerRed selectively expressed in VTA dopamine neurons. The HyPerRed protein has two cysteines with exposed thiol groups attached to a red fluorescent protein. When the two thiol groups are oxidized in the presence of $\mathrm{H}_{2} \mathrm{O}_{2}$, they form a reversible disulfide bond that in turn causes a ratiometric increase in fluorescence; measuring this fluorescence change provides a measure of the relative change in $\mathrm{H}_{2} \mathrm{O}_{2}$ (Ermakova et al., 2014).

As imaged in live brain slices, VTA dopamine neurons in DAT-IRES-Cre mice express the HyPerRed protein (Fig. 4C). Fluorescence intensity was significantly increased by $100 \mathrm{nM}$ nalfurafine as shown in these representative images (Fig. 4C). To confirm HyPerRed sensitivity, slices were treated with $200 \mu \mathrm{M} \mathrm{H} \mathrm{H}_{2} \mathrm{O}_{2}$ after opioid exposure (Fig. 4, C and E, right panels). Nalfurafine caused a consistent, slow onset $\sim 15 \%$ increase in the HyPerRed signal in VTA dopamine neurons, with a peak about 25 minutes after the onset of drug perfusion (Fig. 4D). The nalfurafine-induced increase in HyPerRed fluorescence in VTA cell bodies was not evident in slices pretreated with the nonselective opioid receptor antagonist naloxone (10 $\mu \mathrm{M})$ (Fig. 4, C and D). Both naloxone-nalfurafine and vehicle-nalfurafine samples showed an increased HyPerRed fluorescence signal in response to $200 \mu \mathrm{M} \mathrm{H} \mathrm{H}_{2} \mathrm{O}_{2}$ (Panel 3 of Fig. 4, C and E). Dopamine terminals in the nucleus accumbens of in vitro midbrain slices also expressed the HyPerRed construct and responded to $200 \mu \mathrm{M} \mathrm{H}_{2} \mathrm{O}_{2}$ treatment (Fig. 4E); however, no significant increase in HyPerRed fluorescence in response to nalfurafine was observed in dopamine terminals (Fig. 4, E and F).

\section{Discussion}

In this study, we found that norBNI is an effective longacting antagonist in female mice, when given in repeated, low doses. However, like unbiased KOR agonists, norBNI signaling is disrupted by GRK2-mediated phosphorylation in female mice, likely due to high levels of estradiol. We also found that norBNI effectively blocks KOR activation of GIRK currents in dopamine cell bodies for a week after pretreatment. However, norBNI does not produce a long-lasting block of KORmediated inhibition of presynaptic dopamine terminals. This is in contrast to the long-lasting effects of norBNI in serotonergic terminals (Schindler et al., 2012). Together these data emphasize the importance of somatic KOR on VTA dopamine in mediating the behavioral effects of stress. We also found that nalfurafine, a KOR agonist used to treat pain and itch in humans without psychotomimetic effects or dysphoria (Endoh et al., 2000; Inui, 2015) inhibits dopamine release with higher potency than U50,488, despite its inability to generate aversion or dysphoria. These data further emphasize that presynaptic inhibition of dopamine alone is not sufficient to generate conditioned place aversion or dysphoria in response to KOR agonists.

We found that norBNI is not long-lasting in female mice, unless they are pretreated with CMPD101. This indicates that, as with KOR agonists, interaction between increased estradiol level and GRK2/3 signaling may disrupt the collateral-agonist activity of norBNI in activating JNK. Animals pretreated with norBNI alone had more variance in their tail flick response, indicating this likely is an estrous-dependent effect as was found for agonist active KOR responses in female mice (Abraham et al., 2018). We also would expect, due to this sex difference, that all longacting JNK-dependent antagonists, including JDTic would not work in females during high-estradiol periods of their cycles. We would predict that in humans, JNK-dependent antagonists would potentially be more effective in people taking estradiol-suppressing medications, in menopause, or if taken during low-estrogen points in cycle, which are easier to determine in humans than mice. Regardless, repeated low dose is a more effective dosing regimen because it reduces compliance issues of missing a single dose without as many potential off-target effects of a single high dose of norBNI (Chavkin et al., 2019). This repeated dosing attenuates the sex difference in norBNI's action. It will be important to further assess the effectiveness of low-dose repeated norBNI at blocking behavioral effects of stress such as immobility in forced swim test, especially in females (Laman-Maharg et al., 2018)

Our finding that norBNI acts as a long-acting antagonist blocking the analgesic effects of KOR recapitulate previous results. However, the finding that norBNI does not block KOR inhibition of dopamine terminals is novel and contributes to both our understanding of collateral agonism by compounds like norBNI and subcellular signaling differences. We believe this effect may be restricted not just to terminals, but specifically dopamine neurons. Previous work demonstrated that pretreatment with norBNI 5 days prior blocks the KORmediated increase in serotonin transporter translocation to the membrane in serotonin terminals in the nucleus accumbens (Schindler et al., 2012). We originally predicted that the balance of receptors recycling to the membrane after endocytosis and proteolysis may differ in terminals, leading to sufficient degradation and replacement of KOR in presynaptic terminals that after a week, there were no longer enough "locked" receptors to block inhibition. However, the finding that $\beta$-chlornaltrexamine effectively attenuates KOR inhibition of dopamine release for a week disproves this hypothesis. As such, we predict that this indicates there are differences in the signaling effects of norBNI's collateral agonist activity specifically in dopamine presynaptic terminals. This prediction is further confirmed by the lack of ROS generation in response to nalfurafine in dopamine presynaptic terminals, as compared with the response within the ventral tegmental area. 
We did previously show that norBNI can cause a crossinactivation of the D2 receptor, in dopamine terminals, indicating some amount of receptor inactivation (Schattauer et al., 2017a), but these effects were only measurable in slices taken within an hour of norBNI treatment, indicating that a small, ROS effect may occur, but that it is not sufficient to cause long-lasting inactivation. Dopamine terminals may be either too inundated by ROS, or may too tightly regulate ROS to facilitate JNK-dependent ROS signaling. In a small subcompartment with higher ROS production, the additional ROS generation from norBNI activation of JNK may not be effective to cause depalmitoylation of $\mathrm{G}$ proteins and would not be detectable above baseline values, as measured by HyPerRed. One potential explanation for the inability of norBNI to be long-acting at dopamine terminals is that the biochemical environment is less conducive to ROS-mediated signaling (Stokes et al., 1999; Smythies, 2000). The metabolism of dopamine by monoamine oxidase produces reactive hydrogen peroxide as a byproduct and dopamine can become oxidative itself by generation of dopamine- $O$-quinone (Stokes et al., 1999). Additionally, dopamine neurons have been shown to have more active innate antioxidant activity to counteract ROS generation by catecholamine metabolism (Smythies, 2000). Although we hoped that treatment of slices with sodium ascorbate and thiourea would abrogate these concerns, it is still possible that the ROS levels in dopamine terminals are already too efficiently suppressed to be detected by a cytosolic sensor. Further development of the HyPerRed or related sensors to be membrane targeted may improve our signal to noise in such ROS-sensitive neurons.

In addition to our findings demonstrating the heterogeneity of signaling between cell compartments, the finding that norBNI does not have a long-lasting effect on presynaptic inhibition of dopamine release by KOR generates several key predictions about animal behavior. It has been previously shown that dysphoric components of stress that lead to conditioned avoidance and potentiation of preference for a drug reward depend on KOR on dopamine neurons. norBNI blocks conditioned place aversion to a KOR agonist (5), and the data presented here indicate that this effect cannot be attributed to inhibition of dopamine release. This is further supported by the fact that p38 MAPK is necessary for the aversive effects of KOR, but not necessary for presynaptic inhibition of KOR. Pretreatment with norBNI produces a long-lasting block on increased swim immobility and stress-enhanced cocaine CPP (Chartoff et al., 2012; LamanMaharg et al., 2018), indicating that presynaptic inhibition of dopamine release is not sufficient to cause these effects. As such, we predict that blockade of kappa opioid receptors in nucleus accumbens (NAc) terminals alone would not be sufficient to block behavioral effects of KOR on mood and drug seeking. These findings lead us to predict that G-biased agonists would not be able to produce conditioned place aversion or potentiate drug reward, but would still inhibit dopamine release. Further studies should try to delineate the molecular mechanisms of presynaptic inhibition by KOR to better separate the functional role of this robust physiologic effect.

\section{Acknowledgments}

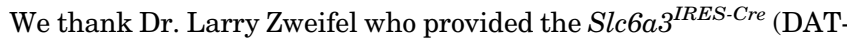
IRES-Cre) mice.

\section{Authorship Contributions}

Participated in research design: Reichard, Land, Chavkin.

Conducted experiments: Reichard, Newton, Rivera, Sotero de Menezes, Schattauer, Land.

Performed data analysis: Reichard, Newton, Schattauer, Land.

Wrote or contributed to the writing of the manuscript: Reichard, Chavkin.

\section{References}

Abraham AD, Schattauer SS, Reichard KL, Cohen JH, Fontaine HM, Song AJ, Johnson SD, Land BB, and Chavkin C (2018) Estrogen regulation of GRK2 inactivates kappa opioid receptor signaling mediating analgesia, but not aversion. $J$ Neurosci 38:8031-8043.

Bruchas MR, Yang T, Schreiber S, Defino M, Kwan SC, Li S, and Chavkin C (2007) Long-acting kappa opioid antagonists disrupt receptor signaling and produce noncompetitive effects by activating c-Jun N-terminal kinase. $J$ Biol Chem 282: 29803-29811.

Buda JJ, Carroll FI, Kosten TR, Swearingen D, and Walters BB (2015) A doubleblind, placebo-controlled trial to evaluate the safety, tolerability, and pharmacokinetics of single, escalating oral doses of JDTic. Neuropsychopharmacology 40: 2059-2065.

Butelman ER, Negus SS, Ai Y, de Costa BR, and Woods JH (1993) Kappa opioid antagonist effects of systemically administered nor-binaltorphimine in a thermal antinociception assay in rhesus monkeys. J Pharmacol Exp Ther 267:1269-1276.

Byers SL, Wiles MV, Dunn SL, and Taft RA (2012) Mouse estrous cycle identification tool and images. PLoS One 7:e35538.

Carlezon WAJ Jr. and Krystal AD (2016) Kappa-opioid antagonists for psychiatric disorders: from bench to clinical trials. Depress Anxiety 33:895-906.

Carroll FI and Carlezon WA Jr. (2013) Development of $\kappa$ opioid receptor antagonists. J Med Chem 56:2178-2195.

Chartoff E, Sawyer A, Rachlin A, Potter D, Pliakas A, and Carlezon WA (2012) Blockade of kappa opioid receptors attenuates the development of depressive-like behaviors induced by cocaine withdrawal in rats. Neuropharmacology 62:167-176.

Chavkin C, Cohen JH, and Land BB (2019) Repeated administration of norbinaltorphimine produces cumulative kappa opioid receptor inactivation. Front Pharmacol 10:88.

Chefer VI, Bäckman CM, Gigante ED, and Shippenberg TS (2013) Kappa opioid receptors on dopaminergic neurons are necessary for kappa-mediated place aversion. Neuropsychopharmacology 38:2623-2631.

Clark JJ, Sandberg SG, Wanat MJ, Gan JO, Horne EA, Hart AS, Akers CA, Parker JG, Willuhn I, Martinez V, et al. (2010) Chronic microsensors for longitudinal, subsecond dopamine detection in behaving animals. Nat Methods 7:126-129.

Di Chiara G and Imperato A (1988) Opposite effects of mu and kappa opiate agonists on dopamine release in the nucleus accumbens and in the dorsal caudate of freely moving rats. J Pharmacol Exp Ther 244:1067-1080.

Ehrich JM, Messinger DI, Knakal CR, Kuhar JR, Schattauer SS, Bruchas MR, Zweifel LS, Kieffer BL, Phillips PEM, and Chavkin C (2015) Kappa opioid receptorinduced aversion requires p38 MAPK activation in VTA dopamine neurons. J Neurosci 35:12917-12931.

Endoh T, Tajima A, Suzuki T, Kamei J, Narita M, Tseng L, and Nagase H (2000) Characterization of the antinociceptive effects of TRK-820 in the rat. Eur $J$ Pharmacol 387:133-140.

Ermakova YG, Bilan DS, Matlashov ME, Mishina NM, Markvicheva KN, Subach OM, Subach FV, Bogeski I, Hoth M, Enikolopov G, et al. (2014) Red fluorescent genetically encoded indicator for intracellular hydrogen peroxide. Nat Commun $\mathbf{5}$ : 5222 .

Fisher AB (2011) Peroxiredoxin 6: a bifunctional enzyme with glutathione peroxidase and phospholipase $\mathrm{A}_{2}$ activities. Antioxid Redox Signal 15:831-844.

Franklin K and Paxinos G (2008) The Mouse Brain in Stereotaxic Coordinates, 3rd ed., Elsevier, New York.

Gold PW, Goodwin FK, and Chrousos GP (1998) Clinical and biochemical manifestations of depression. Relation to the neurobiology of stress. $N$ Engl $J$ Med 319: $348-353$.

Guerrero M, Urbano M, Kim EK, Gamo AM, Riley S, Abgaryan L, Leaf N, Van Orden LJ, Brown SJ, Xie JY, et al. (2019) Design and synthesis of a novel and selective kappa opioid receptor (KOR) antagonist (BTRX-335140). J Med Chem 62: 1761-1780.

Horan P, Taylor J, Yamamura HI, and Porreca F (1992) Extremely long-lasting antagonistic actions of nor-binaltorphimine (nor-BNI) in the mouse tail-flick test. $J$ Pharmacol Exp Ther 260:1237-1243.

Inui S (2015) Nalfurafine hydrochloride to treat pruritus: a review. Clin Cosmet Investig Dermatol 8:249-255.

Kenakin T (2005) New concepts in drug discovery: collateral efficacy and permissive antagonism. Nat Rev Drug Discov 4:919-927.

Kessler RC (1997) The effects of stressful life events on depression. Annu Rev Psychol 48:191-214.

Koob GF (2008) A role for brain stress systems in addiction. Neuron 59:11-34

Laman-Maharg A, Williams AV, Zufelt MD, Minie VA, Ramos-Maciel S, Hao R, Ordoñes Sanchez E, Copeland T, Silverman JL, Leigh A, et al. (2018) Sex differences in the effects of a kappa opioid receptor antagonist in the forced swim test. Front Pharmacol 9:93.

Leander JD (1988) Buprenorphine is a potent kappa-opioid receptor antagonist in pigeons and mice. Eur J Pharmacol 151:457-461.

Lemos JC, Wanat MJ, Smith JS, Reyes BAS, Hollon NG, Van Bockstaele EJ, Chavkin C, and Phillips PEM (2012) Severe stress switches CRF action in the nucleus accumbens from appetitive to aversive. Nature 490:402-406. 
Lowe JD, Sanderson HS, Cooke AE, Ostovar M, Tsisanova E, Withey SL, Chavkin C, Husbands SM, Kelly E, Henderson G, et al (2015) Role of G Protein-Coupled Receptor Kinases 2 and 3 in $\mu$-opioid receptor desensitization and internalization. Mol Pharmacol 88:347-356.

Margolis EB, Lock H, Chefer VI, Shippenberg TS, Hjelmstad GO, and Fields HL (2006) Kappa opioids selectively control dopaminergic neurons projecting to the prefrontal cortex. Proc Natl Acad Sci USA 103:2938-2942.

Melief EJ, Miyatake M, Carroll FI, Béguin C, Carlezon WA Jr., Cohen BM, Grimwood S, Mitch CH, Rorick-Kehn L, and Chavkin C (2011) Duration of action of a broad range of selective $\kappa$-opioid receptor antagonists is positively correlated with c-Jun N-terminal kinase-1 activation. Mol Pharmacol 80:920-929.

Rice ME (1999) Use of ascorbate in the preparation and maintenance of brain slices. Methods 18:144-149.

Rorick-Kehn LM, Witcher JW, Lowe SL, Gonzales CR, Weller MA, Bell RL, Hart JC, Need AB, McKinzie JH, Statnick MA, et al. (2014) Determining pharmacological selectivity of the kappa opioid receptor antagonist LY2456302 using pupillometry as a translational biomarker in rat and human. Int J Neuropsychopharmacol 18:pyu036.

Schattauer SS, Bedini A, Summers F, Reilly-Treat A, Andrews MM, Land BB, and Chavkin C (2019) Reactive oxygen species (ROS) generation is stimulated by $\mathrm{k}$ opioid receptor activation through phosphorylated c-Jun N-terminal kinase and inhibited by p38 mitogen-activated protein kinase (MAPK) activation. J Biol Chem 294:16884-16896.

Schattauer SS, Kuhar JR, Song A, and Chavkin C (2017a) Nalfurafine is a G-protein biased agonist having significantly greater bias at the human than rodent form of the kappa opioid receptor. Cell Signal 32:59-65.

Schattauer SS, Land BB, Reichard KL, Abraham AD, Burgeno LM, Kuhar JR, Phillips PEM, Ong SE, and Chavkin C (2017b) Peroxiredoxin 6 mediates Goi protein-coupled receptor inactivation by cJun kinase. Nat Commun 8:743.
Schindler AG, Messinger DI, Smith JS, Shankar H, Gustin RM, Schattauer SS, Lemos JC, Chavkin NW, Hagan CE, Neumaier JF, et al. (2012) Stress produces aversion and potentiates cocaine reward by releasing endogenous dynorphins in the ventral striatum to locally stimulate serotonin reuptake. $J$ Neurosci 32: 17582-17596.

Schoenecker JW, Takemori AE, and Portoghese PS (1987) Opioid agonist and antagonist activities of monofunctional nitrogen mustard analogues of betachlornaltrexamine. J Med Chem 30:933-935.

Smith CB, Medzihradsky F, Hollingsworth PJ, DeCosta B, Rice KC, and Woods JH (1990) Nor-binaltorphimine is a reversible, noncompetitive opioid antagonist in the mouse vas deferens with high affinity for kappa receptors in monkey brain membranes. Prog Clin Biol Res 328:65-68.

Smythies J (2000) Redox aspects of signaling by catecholamines and their metabolites. Antioxid Redox Signal 2:575-583.

Stokes AH, Hastings TG, and Vrana KE (1999) Cytotoxic and genotoxic potential of dopamine. J Neurosci Res 55:659-665.

Ting JT, Daigle TL, Chen Q, and Feng G (2014) Acute brain slice methods for adult and aging animals: application of targeted patch clamp analysis and optogenetics. Methods Mol Biol 1183:221-242.

Zhuang X, Masson J, Gingrich JA, Rayport S, and Hen R (2005) Targeted gene expression in dopamine and serotonin neurons of the mouse brain. $J$ Neurosci Methods 143:27-32.

Address correspondence to: Dr. Charles Chavkin, Department of Pharmacology, Box 357750, University of Washington School of Medicine, Seattle, WA 98195-7750.E-mail: cchavkin@uw.edu 